\title{
XXVI. On the size best adapted for achromatic glasses; with hints to opticians and amateurs of astronomical studies, on the construction and use of telescopes in general
}

\section{W. Kitchener M.D.}

To cite this article: W. Kitchener M.D. (1815) XXVI. On the size best adapted for achromatic glasses; with hints to opticians and amateurs of astronomical studies, on the construction and use of telescopes in general , Philosophical Magazine Series 1, 46:208, 122-129, DOI: $10.1080 / 14786441508638509$

To link to this article: http://dx.doi.org/10.1080/14786441508638509

\section{冓 Published online: 27 Jul 2009.}

Submit your article to this journal ए

\section{山ll Article views: 2}

Q View related articles ¿ 


\section{On the Size lest adupled for Achromatic Glasses}

Fig. 1 . In this the imer cylinder represents the working cylinder filled with oil, or any other fuid body, (perhaps water migitt be found to answer) up to the piston, with a portion of the same fluid over the piston. This cylinder having no bottom, the same fiuid stands between it and the next cylinder (which Mr. Woolf calls his receiver) at a height proportioned to the distance of the piston from the top of its stroke. The outer cylinder in this figure shows the steam-case.-This is his arrangement for working by the pressure of the atmosphere. The steam being admitted only into the receiver, causes the oil or water to descend therein and rise into the working cylinder carrying the piston before it; when (the communication with the condenser being opened) a vacuum being formed, the oil or other fluid ascends in the receiver, and the piston then descends, when a fresh charge of steam is admitter, and the stroke of the engine repeated.

Fig. 2 difiers from fig. 1 only in having the receiver placed beside the working cylinder, instead of inclosing the latter. For our part, we prefer the first arrangement.

When the engine is to be worked by steam upon the piston, instead of the atmosphere, then the working cylinder as well as the receiver must be covered, and the working cylinder, like the receiver, must have a communication with the condenser.

The advantage which Mr. Woolf's new improvement promises is, the impossibility of any steam being wasted by passing the piston-a source of more waste than is generally imagined.

*** In the plate of Mr. Woolf's boiler given in our last, the top of the boiler, fig. 3, was, by a mistake of the engraver, carried over the top of the brick-work. It should have been carried only to the inner edge of the brick-work.

XXVI. On the Size best adapled for Achromatic Glasses; with Hints to Opticians and Amalen's of astronomical Studies, on the Construction and Use of Telescopes in general. By W. Kitchener, M.D.*

$\mathbf{I}_{\mathrm{N}}$

N reflecting-telescopes, Dr. Herschel says, the maximum of distinctness is much easier obtained in a speculum of six inches and a quarter aperture than in larger ones; and this was the size of the telescope he made his astronomical catalogues with, and in his hands it has worked wonders. Dr. H. observes, that the

* The greater part of this paper was originally published in "Practical Observations on Teifscopes," by the same Author, which was noticed in the Philosophical Magazine for Dccember 1814. The present paper is intended to form purt of an enlarged and improved edition of the above work now preparing for the press by the learned author. 
seven feet Newtonian has sufficient lirht with a single eye-glass, which gives it a magnifying power of 287 , to show the belts and double ring of Saturn completely well. What can we wish for more? How many have expended large sums of money on telescopes, without having ever seen such an all-repaying sight!

Query: Can the acme of perfection be obtained in metals of larger diameter? Sevcral of our first-rate practical and woiking opticians have candidly declared to me, they would not, for general sale, undertake to make speculums of larger size than nine inches, that would show a star round and neatly: and unless they will bear this grand ordeal, it has been the fashion, lately, to suppose its figure camnot be depended on for exhibiting any object with that faithful accuracy which is the sine guê non of astronomical instruments.

That distinctness of vision appearing to be so limited, may not create cne sigh from the breast of any minute philosopher, that further optical assistance camnot be given to his eye; and that art is, as I have before said, so circumscribed; I will venture to account for these imperliments and boundaries from the operations of Nature herself; i.e. the rapid rotatory motion of the earth preventing the application of a higher power than 300 times being used with any advantage. This is so true, that, until this obstacle is removed, we need not hunt after monstrous telescopes, unless it be in the true holbby-horsical spirit, for the sake of the pleasure arising from the trouble of using them, and being disappointed. Beyond a certain size, telescopes are only just as useful, as the enormous spectacles which are suspended over the doors of opticians.

When the inventors of the achromatic glasses fixed the powers of their telescopes, it was no doubt done after due deliberation, and a conviction arising from experiment, that for planetary uses the proportion of the pencil of rays to the diameter of the object-glass was most proper when as forty to one, i.e. for common telescopes and common observers. Thus the thirty-inch, with two inches aperture, magruifies cighty times; and it nay be considered a general rule, that to find the most effective magnifying power of a telescope for planetary use, multiply the diameter of the object-glass by forty or fifty: to bear more it must be a very fine instrument, and the planet near the meridian; by the proximity of the object to which, the application of magnifying power must always be governed. When the pencil is much less than one-fiftieth of an inch diameter, it is too diluted to perfectly excite the action of the eye: and, when applied to the planets, we lose in distinctress more than we gain, by the magnifying being in too high a ratio to the illuminating power. But we must take into the account not only the bigness but the bright- 


\section{On the Size best adapted for Achromatic Glasses.}

ness of the pencil of rays, which will of course be in proportion to the brilliance of the object observed.

Some stars I have observed with a power which diminished the diameter of the pencil to nearly one hundred-and-twentieth of an inch; i.e. a power of 420 , with an aperture of three inches and five-eighths diameter in the clear. I have never yet seen any object that appeared to require a greater power; and it requires a most perfect telescope, and every other favourable circumstance, to admit of this being used with any advantage. From the rapidity of the diumal motion of the earth, the limited excitability of the eye, the impediments to vision arising from our magnifying the atmospheric medium we look through, in proportion as we magnify the object we look at, increase in so high a ratio to the magnifying power, that more than 100 for terrestrial and 300 for astronomical use rather imperle than assist vision. And again, when we charge our telescopes with a higher power than 300 times, what very uncommon dexterity is required either to find the object, or manage the instrument! It is indeed fortunate that a higher maguifier is rarely neerlful, as it cannot be used to much advantage till the atmosphere be removed, and the earth stands till.

With a good achromatic of forty-six inch focus, and a treble object-glass of three inches and five-eighths in the clear aperture, I have seen that most minute point of light near the polestar, with the following powers, measured by a dynameter invented and made by the late ingenious Mr. Ramsden : 40, 80, $150,850,350,420,700$; and even with 1123 times the small star was still visible. Mr. William Walker, the astronomer, was observing with me, and also saw this. Mr. Charles Fairbone, mathematical-instrument maker, of Great New-Strect, FetterLane, saw it again very listinctly on the 30th August 1807. Mr. Samuel Pierce, telescope-maker, at Mr. Berge's, optician, Piccadilly, observed the same on the 26 th May 1811. I believe the polar star is as proper as any, for a test of the perfection of a telescope, as to its light and distinctness; and as it is easily found, and always visible, it is the more desirable, as it is a more universally attainable test.

I mention the foregoing observations merely as an authenticated and curious fact, how far magnifying power could be carried on this object, as it was with evident detriment to vision when higher than 80 , which showed this star more pleasantly, and the illuminating and magnifying powers for this object appeared to be in more perfect proportion than with any of the higher or the lower powers.

We should never use a greater magnifier than we absolutely want; the lower the power, the more beautiful and brilliant the object 
object appears : the field of view is proportionately large, and uniformly good and dis:tinct, and tlis motion of the oljects passing it proporticnateiy less: thus they may be observed with greater ease and quiet attention. But here it may be well to observe, there is no use in the pencil of rays being of latger diameter than the optic pupil, which 's commonly calculated it one-tenth of an ineb, varying in magnitude according to the brightness or obsenity of the object presencie to it. The natural atute appears to be that of dilsusion; and the contraction, 3 state of violence produced by wir efort originating in the mind: when the light is too strong, or the object too hright, we contract the pupil to intercept that excess of light which wotid injure the eye: when the light is faint, the pupil espands, that a greater quantity of light may enter the eye, and thus make a stionger impression upon it. This contraction and dilation of the pupil may be observed by holining a lovking,glass (or, what is still better, the lowest small sueculum of a Gregorian telescope) before the eye at a windows sind turning gradually from it, continually looking at the eyc. It may be more easily and perfectly seen by attentively watching the eve of aunther. I think it is most agreeably cbserver in a fine fuil blue eye.

To ascertain the magniying power of a telescope, if we measure the diameter of the ape:ture of the objact-glas or speculum, and that of the litcle inage of it which is forned at the end of the eye-piece, the proportion between these will give the ratio of the magnifying powar. To measure the dimeter of the pencil of rays with great ease and sccuracy, Mr. Ramsden about the year 1775 contrived a clever iitle instrument, which he called a dynameter; for though, when single lenses are used, the power of a glass is readily discovered by dividing the focal length of the object-glass by that of the eye-glass, -in eye-pieces of the common consizution, especially those of a negative focus, it is very difficult to measure in this manner; nor can it be done with any aceuracy with those eye-pieces which are made for erect vision with four eye-glasses.

The dynameter is principally composed of a fine micrometer screw, and a divided plano-convex glass; by means of which the inage of the pencil of rays is completely scparated, and the diameter of it known to the greatest nicety. The wheel or head of the micrometer is divided into a hundred equal parts, and a figure engraven over every fifth division, which is cut rather longer than the others; 1,2,3, and so on to 20: but adding an 0 to each figure in calculating, it will then read off, $10,20,30$, and so on to 200 . The nonius is divided into 15,10 , towards 0 , and $\mathbf{5}$ on the contrary side.

The revolutions of the micrometer head will bring the edge of 


\section{I26 On the Size lest adapted for Achromatic Glasses.}

the circle round it, and the division on the nonius, to coincide at 10: eacla division, therefore, is equal to the ten thousandth prart of an inch.

Applying this little instrument to the eye-glass of a telescope, when adjusted to distinct vision at any distant object, and turning the micrometer head, the emergent pencil will begin to separate; and when the extrente edges are brought into contact, the number of divisions will show the dianeter of ic in thousandths of an inch; then reduce the diameter of the object-glass into thousands, and divide that sum by the diameter of the pencil, the quotient will be the real magnifying porver. But as it is requisite for the emergent pencil of rays to be in the focus of the divided glass, a thin transparent piece of irory, precisely onetenth of an inch in diameter, is set in the sliding cover, to adjust for that distance, which must always be done before it can be used with accuracy.

When this transparent piece of ivory is brought over the hole in the cover of the dynameter, and appears perfectly round, the nonius will then be at 0 , and is properly adjusted. Five revolutions of the micrometer screw will make a complete separation of the diameter of its aperture, which is one-tenth of an inch : and when the opposite silcs are brought into contact, the nonius will coincide at the fifth division of it, which is five two-hundredths of an inch; thus rividing each tenth of an inch into a thousand equal parts. Another method of discovering the magnifying power, is to set the teleseope in such a position opposite the sun, that the rays of light may fall perpendicularly on the object-glass; and the pencil of rays may be received on a piece of paper, and its diameter measured: then, as the diameter of the pencil of rays is to that of the object-glass, so is the magnifying power of the telescope. Or, thirdly, a thin piece of mother of pearl, with a very acute angle two inches long marked thereon, and only one-tenth of an inch at its base marked thereon; the length being divided into ten crual divisions, making a visible line to each division, with a figure over it, - these divisons will express or show the hundresths of an incli: apply this scale to the eye-tulie of the telescope, observe where the emergent pencil of rays fills up a certain space at or near any of the divisions; multiply tine dinmeter of the olject-glass into hundredths on the scale, and the quotient will be the magnifying power.

Before any of these methods of finding the magnifying power be made use of, remember to look through the tube, and observe carefully if some of the object-glass be not cut off, and part of the original persil intercepted by the stops in the tube, \&c. This is a very common trick, and will render your calculation on the whole aperture erroneous ; for in all cases the magnifying power 
of telescopes, or microscopes, is measured by the proportion of the diameter of the original pencil to that of the pencil which enters the eye.

The degree in which magnifying power may be advantageously applied, depend:s so much on the perfection of the telescope and the state of the atmosphere, that it is hardly possible, by any general rules, to fix precise limits to it : but, to afford an opportunity of trying this and many other entertaining experiments, the day eyc-piece should have a pipe-drawer; and the screw, which receives the tube containing the two first glasses, should be the same as the screw which fixes the eye-drawer to the telescope : and the two first eye-glasses should be made to separate (by a sliding tube within the pipe-drawer) from the third ans fourth. This will give a very pleasing variety, and be extremely convenient to those who wish to obtain a certain, exact degree 0 . magnifying power.

For large adjustments, and also that the telescope may be used for near objects, and occasionally be made to supply the place of a microscope, it should have a sliding tail-piece; and the tooth and pinion for the fine adjustment should be made carefully, so as to move easily and smoothly, that it may not shake the glass while adjusting it. This is one of those defects we must expect to find in instruments which are so very rarely used by those who make them - the workman not being aware of the great importance of the telescope being perfectly steady during the adjustment of the focus. For this purpose, there should be two steadying sliding tubes applied from the eye-end of the telescope to the stand. These will in great measure prevent the vibrations, which are sich impediments to vision. When the eye is perfectly satisfied with the adjustment of the focus, let the telescope be so placed that the object may pass through the field, the instrument remaining at rest during the time: this answers better than running after it with rack-work.

The telescope should be suspended in the centre of gravity, and mounted on a portable and folding mahogany stand, with divided circles, and an universal polar adjustment. If the instrument be then placed in the plane of the equater, only one motion will be required to follow the object; which, when large magnifiers are used, is a very great advantage, as the tremors occasioned by the movenent of the rack-work are of course proportionably diminished. And be it always remembered, that steadiness is of the first importance. When high magnifiers are used, we need every assistance that can be contrived; as, even with the best constructed stands, a person walking in the room will prevent our secing distinctly; nay, the very pulsation in the 


\section{On the Size best adapted for Achromatic Glasses.}

hody of the observer will sometimes agitate the floor enough to produce this effect.

The atmosphere always appears most diaphanous on those evenings when there is least wind; and vision seems better, perhaps, hecause the instrument is still. For this reason, and to aroid currents of air passing before the glass, whenever the weather will permit, let the telescope be taken out of doors; for it will never do its utmost unless it is placed on the ground, in the open air. If the instrument has been kept in a room, the temperature of which is much warmer than the open air, I usually take off the cap of the object end, and take out the eye-piece, and let the air pass through the tube for ten minutes; and for at least the same space of time we must carefully avoid all stimulating and bright objects; so that the pupil may be in its most expanded state. When the eye is thus prepared, the sensibility of the visual organ will be much increased. I have also found it very advantageous to occasionally rest the eye for a few minutes: this will restore its irritability, which is soon exhausted when stimulated by an intensely bright object: and when a light is necessary to find an eye-piece, or rectify the iustrument, to prevent the adjustment of the eye being disturbed, 1 use a small lantern, which gives a very faint light only on one side, and that may be made dark.

For those who have not courage, or constitution, to brave the inclemency of midnight frosts and damps, the most steady way of supporting a telescope within doors, is by a clamp made to fasten on the sashes when the top sash is put down: the objectend of the telescope is then in the open air, and out of reach of the undulating motion occasioned by looking through a medium of atmosphere which is undergoing a change of temperature, by the cold air rushing into the warm roon. By this contrivance we have almost all the steadiness of being on the ground, without being exposed to the cold, \&c.

I must here endeavour to impress on the mind of my readers another most important observation: when they have done using the telescope, let the olject-glass be taken ont and laid in a dry warm place, for a sulficient time to exaporate the damp air; which on dewy crenings too plentifully condenses on the objectglass; and however closely the lenses constituting the objectglass are burnished into the brass cell, unless they are very carefully kept dry, the damp air will penetrate between the glasses, and produce a sort of fog, or sometimes an arborescent vegetation like sea-weed, which I have seen spread all over the objectglass. Unless these evils exist in a very extreme degree, experience has proved the only detrinent they do to the perform-

ance 
ance of the glass is, that it does not transmit quite so much light: and if the instrument be a very fine one, it is more adrisable to put up with an almost inperceptible diminution of its brilliancy, than run the risk of ciestroying the telescope-for the objectglasses cannot be seyarated from each other, without perhaps irreparably disordering the aljustment ; from the perfect harmony of which, the instrument may, possibly, in a great measure derive its superior excellence, fron certain circumstanes, which once disturbed can never be restored-the acme of perfection being alvays aacidental.

Moreover, it is equally indispensable, when we wish to discern those delicate and minute objects which are the most interesting and curious exhibitions our telescopes display to us, and with the finest instruments are only discernible with the most favourable circumstances, that we should be in a position of the greatest ease: no cramp or painful posture must distort the body, or irritate the mind; the whole powers of which must be concentrated in the eye: for such is the sympathy between the various organs of the human body, that we way as well attempt to think accurately on two subjects at the same time, as to use two senses at the sane moment:-each must be used alone. As our immortal Shakespeare has obscrved of listening, with such profound attention, that " each other sense was lost in that of hearing."

The sinallest achromatic that can be used with effect for astrononical purposes is the three-and-a-latf fret. These telescopes were originally furnished with thres object-glasses of three inches and three-quarters dianeter; but they are now nually made with two object-glasses of two inclies and three-quarters aperture. With this telescope all the principal and most interesting? celestial phanomena may be pleasantly observed: and indeed, if exquisitely perfect, it will discover the minutest objects in the heavens: and as there are more made of this than of the largersized telescopes, it is proportionably more easy to ohtain a rool one. In astronomical as well as in all other concerns, truth and perfection are the first desiderata: our telescopes only delude us, unless, like the juryman's oath, they display the truth, and nothing but the truth. And, in future, I hope astronomical amateurs will rather seek for perfect telescopes than large ones; for, as the pupil of the eye contracts and dilates pro re-nata, bright objects would often be better seen by reducing the aperture, than by loading the telescope with magnifying pover to save the eye from being drowned in liglst. 